\title{
STATISTICAL ANALYSIS OF FAILURE CONSEQUENCES FOR OIL AND GAS PIPELINES
}

\author{
CHIARA BELVEDERESI \& MARKUS R. DANN \\ Department of Civil Engineering, University of Calgary, Calgary, Canada.
}

\begin{abstract}
Pipelines are among the safest methods to transport oil and gas, but when an incident occurs, it can lead to disaster. Pipeline failures often cause injuries, fatalities, explosions and fires due to product ignition, property damage, and spills that can lead to environmental impact. The likelihood and consequence analyses of pipeline failures from past events are necessary for the development of realistic risk models. For this reason, a statistical analysis of failure consequences between 2010 and 2015 based on the Pipeline and Hazardous Materials Safety Administration (PHMSA) database is provided in this paper. Relationships between the pipeline failure consequences and the basic pipeline design variables are investigated. They provide a valuable contribution to pipeline risk modeling. Results show that recently installed hazardous liquid pipelines of large diameters and high operating pressure are more likely to cause ignitions. In contrast, older installed hazardous liquid pipelines of small diameters cause larger release volumes and more expensive property damages. The portion of fatalities and injuries that is caused by distribution pipeline accidents is higher for the public than workers compared to other pipeline types.

Keywords: consequences, pipeline, pipeline failure, risk, statistical analysis.
\end{abstract}

\section{INTRODUCTION}

The International Energy Outlook 2016 [1] estimates that the worldwide consumption of fossil fuels will increase from 90 million barrels per day in 2012 to 121 million barrels per day in 2040. The growth in demand for these fuels increases the importance of identifying, analyzing and evaluating the risks associated with the transportation of combustible materials.

Oil and gas pipelines play a significant role in our society; they are among the safest methods for transporting oil and gas. However, accidents occur and they can lead to significant consequences.

Data related to pipeline accidents in the United States are collected by the Pipeline and Hazardous Materials Safety Administration (PHMSA) of the US Department of Transportation (DOT). PHMSA provides accident details, annual summaries, multi-year trends of safety performance metrics and pipeline mileages. Pipelines operators are required to submit annual reports by the Code of Federal Regulations (49 CFR Parts 191, 195) to PHMSA. These reports, which contain pipeline information, accident preventive actions and post-accident response, are useful for researchers, governmental agencies and industry professionals, for inspection planning and risk assessment.

This paper presents a statistical analysis of the oil and gas pipeline failures in the United States from 2010 to 2015 based on the PHMSA database. The analysis focuses on the relationships between pipeline design variables and common consequences of pipeline accidents, such as ignition, injuries and fatalities, property damage and spilled volume. Risk models can be developed based on such relationships.

The paper is organized as follows. Section 2 presents the PHMSA accident reporting criteria and an overview of the basic pipeline design variables. Section 3 shows the results of 
the analysis of accidents consequences with a focus on ignition, injuries, fatalities, property damage and spilled volume. Conclusions and future developments are presentd in Section 4.

\section{PHMSA DATA COLLECTION}

Approximately $3.7 \times 10^{6} \mathrm{~km}$ of gas transmission and gathering, gas distribution and hazardous liquid pipelines cross the US. PHMSA regulates approximately $76 \%$ of the total length of pipelines in the US [2]. The pipeline network is divided into three main types: gathering, transmission and distribution pipelines. Gathering pipelines transport materials form production wells to processing facilities; afterwards, transmission pipelines carry oil and gas for long distances from processing facilities to many locations in the US and, eventually, fuels reach customers through distribution pipelines.

PHMSA maintains an oil and gas pipeline accident database since the 1980s [3]. Reporting criteria have changed over time. Incidents between 2010 and 2015 are considered in this study for all pipeline types because events contained in this time window are consistent within the same reporting criteria described in the next section.

\subsection{Accident reporting criteria}

Operators under the PHMSA jurisdiction must submit a form no later than 30 days after the accident is detected. Title 49 of the Code of Federal Regulations [4] contains reporting criteria for all types of pipelines.

According to Title 49 CFR $\$ 191.3$ for gas transmission, gathering and distribution pipeline, an accident must be reported if it involves a release of gas from a pipeline, or a liquefied natural gas, liquefied petroleum gas, refrigerant gas, or gas from a liquefied natural gas facility. An accident must result in one or more of the following outcomes to be reported:

(i) a death, or personal injury necessitating in-patient hospitalization;

(ii) estimated property damage of $\$ 50,000$ or more, including loss to the operator and others, or both, but excluding cost of gas lost;

(iii) unintentional estimated gas loss of three million cubic feet or more;

Similarly, an event that results in an emergency shutdown of a liquefied natural gas facility must be reported as well as an event that is significant in the judgment of the operator, even though it does not meet the aforementioned criteria.

Title 49 CFR $\$ 195.50$ defines accidents for hazardous liquid pipelines. An accident report is required if a release of the hazardous liquid or carbon dioxide transported results in:

(a) explosion or fire not intentionally set by the operator.

(b) release of 5 gallons (19 litres) or more of hazardous liquid or carbon dioxide, except that no report is required for a release of less than 5 barrels ( 0.8 cubic meters) resulting from a pipeline maintenance activity if the release is:

(1) not otherwise reportable under this section;

(2) not one described in $§ 195.52(a)(4)$;

(3) confined to company property or pipeline right-of-way; and

(4) cleaned up promptly;

(c) death of any person;

(d) personal injury necessitating hospitalization; 
(e) estimated property damage, including cost of clean-up and recovery, value of lost product, and damage to the property of the operator or others, or both, exceeding $\$ 50,000$.

Table 1 summarizes the reporting criteria for gas gathering, transmission, distribution lines and hazardous liquid pipelines.

\subsection{Pipeline design variables}

Pipeline operators are required to provide details about the pipeline design characteristics when they complete the incident form. In this paper, the class location, installation year, pipe diameter, and maximum allowable operating pressure are considered because they are the basic variables to characterize the design of a pipeline.

\subsubsection{Class location}

Section $\$ 192.5$ CFR defines a class location unit as an onshore area that extends $200 \mathrm{~m}$ on either side of the centreline of any continuous $1.6 \mathrm{~km}$ length of pipeline. In total, there are four class locations organised as follows [4]:

1. Class 1 location

a. An offshore area; or

b. Any class location unit that has 10 or fewer buildings intended for human capacity.

2. Class 2 location includes any location unit that has more than 10 but less than 46 buildings intended for human occupancy

3. Class 3 location

a. Any class location unit that has 46 or more buildings intended for human occupancy: or

b. An area where the pipeline lies within $91 \mathrm{~m}$ of either a building or a small, welldefined outside area (such as a playground, recreation area, outdoor theatre, or other place of public assembly) that is occupied by 20 or more persons on at least 5 days a week for 10 weeks in any 12-month period. (The days and weeks need not be consecutive.)

Table 1: Oil and gas pipelines failures reporting criteria.

\begin{tabular}{lll}
\hline & $\begin{array}{l}\text { Gas gathering, transmission and } \\
\text { distribution pipelines }\end{array}$ & Hazardous liquid pipelines \\
\hline Title 49 CFR & $\S 191.3$ & $\$ 195.50$ \\
Death & Yes & Yes \\
Injury & Yes & Yes \\
Property & $\geq \$ 50000$ (not considering cost of gas & $\geq \$ 50000$ (considering cost of \\
damage & lost) & product lost) \\
Release & Gas loss $\geq 3$ million $\mathrm{ft}^{3}$ & Product loss $\geq 5$ gallons \\
Explosion & No & Yes \\
Fire & No & Yes \\
Other & Liquefied natural gas facility shutdown & No \\
\hline
\end{tabular}


4. Class 4 location is any class location unit where buildings with four or more stories above ground are prevalent.

The length of Class locations 2, 3 and 4 may be adjusted as follows:

1. A Class 4 location ends 220 yards $(200 \mathrm{~m}$ ) from the nearest building with four or more stories above ground.

2. When a cluster of buildings intended for human occupancy requires a Class 2 or 3 location, the class location ends 220 yards $(200 \mathrm{~m})$ from the nearest building in the cluster.

\subsubsection{Installation year}

The installation year reported in the database indicates the year when part of the system involved in the accident was installed. In this paper, installation years were divided into decades for the only purpose of a better comprehension of results. It must be noted that information on installation year in the accident database is often missing and this may lead to bias in the results.

\subsubsection{Pipeline diameter}

The size of pipelines is identified by the nominal pipe size (NPS) [5]; NPS refers to the North American set of standard pipeline sizes. Pipeline diameters were divided into three groups for gas transmission and gathering, gas distribution, and hazardous liquid pipelines. Table 2 shows for each pipeline type the range selected and the number of accidents under each range. The criterion to select each range is based on the number of occurrences so that each group contains a comparable number of cases. As for the installation year, missing information on pipeline diameter may cause bias in the results.

\subsubsection{Maximum allowable operating pressure (MAOP)}

According to the Code of Federal Regulations (CFR) Title 49 §192.619 [4], no person may operate a segment of steel or plastic pipeline at a pressure that exceeds a maximum allowable operating pressure (MAOP).

In order to facilitate the comparison among failure pressures, MAOP were divided into three groups, similarly to the pipe diameter. Table 3 shows pressure ranges and number of cases for each range per pipeline type.

Table 2: Pipe diameter ranges per pipeline type.

\begin{tabular}{llllll}
\hline & & $\begin{array}{l}\text { Gas transmission } \\
\text { pipeline }\end{array}$ & $\begin{array}{l}\text { Gas distribution } \\
\text { pipeline }\end{array}$ & $\begin{array}{l}\text { Gas gathering } \\
\text { pipeline }\end{array}$ & $\begin{array}{l}\text { Hazardous } \\
\text { liquid pipeline }\end{array}$ \\
\hline \multirow{2}{*}{ D1 } & range [in] & {$[0,12]$} & {$[0,2]$} & {$[0,10]$} & {$[0,8]$} \\
& number of cases & 127 & 172 & 12 & 161 \\
D2 & range [in] & $(12,21]$ & $(2,5]$ & $(10,14]$ & $(8,12]$ \\
& number of cases & 130 & 77 & 14 & 188 \\
D3 & range [in] & $(21,42]$ & $(5,30]$ & $(14,26]$ & $(12,48]$ \\
& number of cases & 97 & 130 & 12 & 204 \\
\hline
\end{tabular}


Table 3: Maximum allowable operating pressure (MAOP) ranges per pipeline type.

\begin{tabular}{|c|c|c|c|c|c|}
\hline & & $\begin{array}{l}\text { Gas transmission } \\
\text { pipeline }\end{array}$ & $\begin{array}{l}\text { Gas distribution } \\
\text { pipeline }\end{array}$ & $\begin{array}{l}\text { Gas gathering } \\
\text { pipeline }\end{array}$ & $\begin{array}{l}\text { Hazardous } \\
\text { liquid pipeline }\end{array}$ \\
\hline \multirow{2}{*}{ P1 } & range [psig] & {$[0,800]$} & {$[0,40]$} & {$[0,1100]$} & {$[0,280]$} \\
\hline & number of cases & 278 & 202 & 15 & 497 \\
\hline \multirow{2}{*}{$\mathrm{P} 2$} & range [psig] & $(800,1000]$ & $(40,60]$ & $(1100,1400]$ & $(280,980]$ \\
\hline & number of cases & 190 & 318 & 30 & 517 \\
\hline \multirow{2}{*}{ P3 } & range [psig] & $(1000,2600]$ & $(60,880]$ & $(1400,5000]$ & $(980,3600]$ \\
\hline & number of cases & 216 & 129 & 21 & 578 \\
\hline
\end{tabular}

\section{ANALYSIS OF INCIDENT EVENTS}

\subsection{Annual failure rate}

The annual pipeline failure rate indicates the frequency with which the pipeline system fails per year. It is calculated as the annual number of accidents over the mileage. Figure 1 shows the annual failure rate per pipeline category; distribution pipelines have the lowest failure with nearly constant rates between $2.9 \times 10^{-5}$ and $3.6 \times 10^{-5}$ accidents per km per year. In contrast, hazardous liquid pipelines have the highest failure rates around $1.2 \times 10^{-3}$ to $1.4 \times 10^{-3}$ accidents per $\mathrm{km}$ per year in the recent past. Incidents often led to major consequences, such as ignitions, injuries, fatalities, property damage and release of product. The next sections investigate the relationship between pipeline incident consequences and pipe design variables, such as class location, installation year, pipeline diameter and maximum allowable operating pressure.

\subsection{Annual ignition rate}

The occurrence of product ignition is a possible failure outcome. Figure 2 shows the annual ignition rate per pipeline type. Hazardous liquid pipelines have the highest ignition rates. The ignition rate increases compared to the failure rate with the exception for 2015. For this

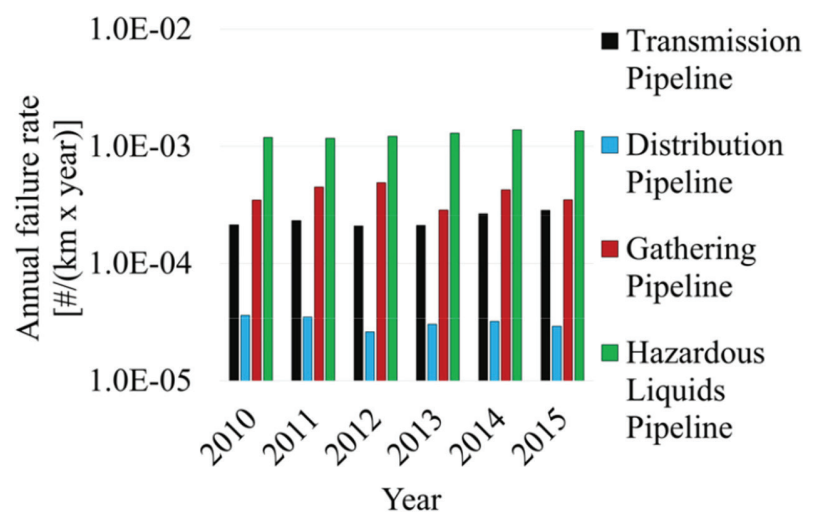

Figure 1: Annual failure rate per pipeline type. 


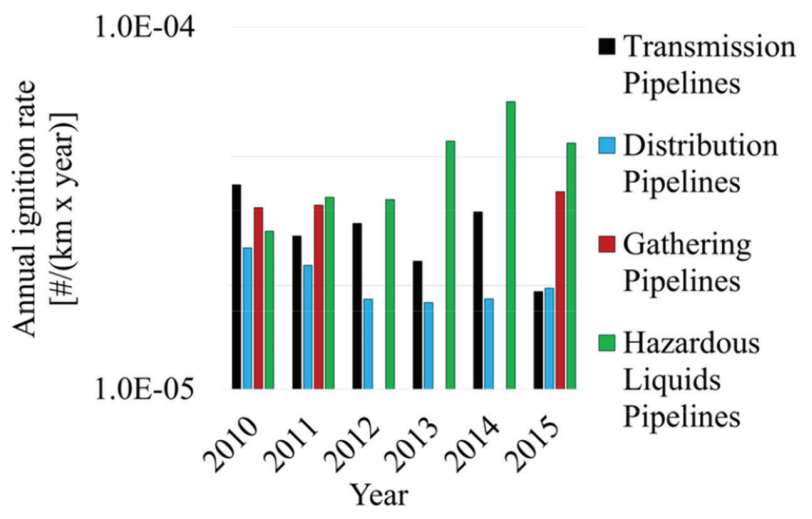

Figure 2: Annual ignition rate per pipeline type.
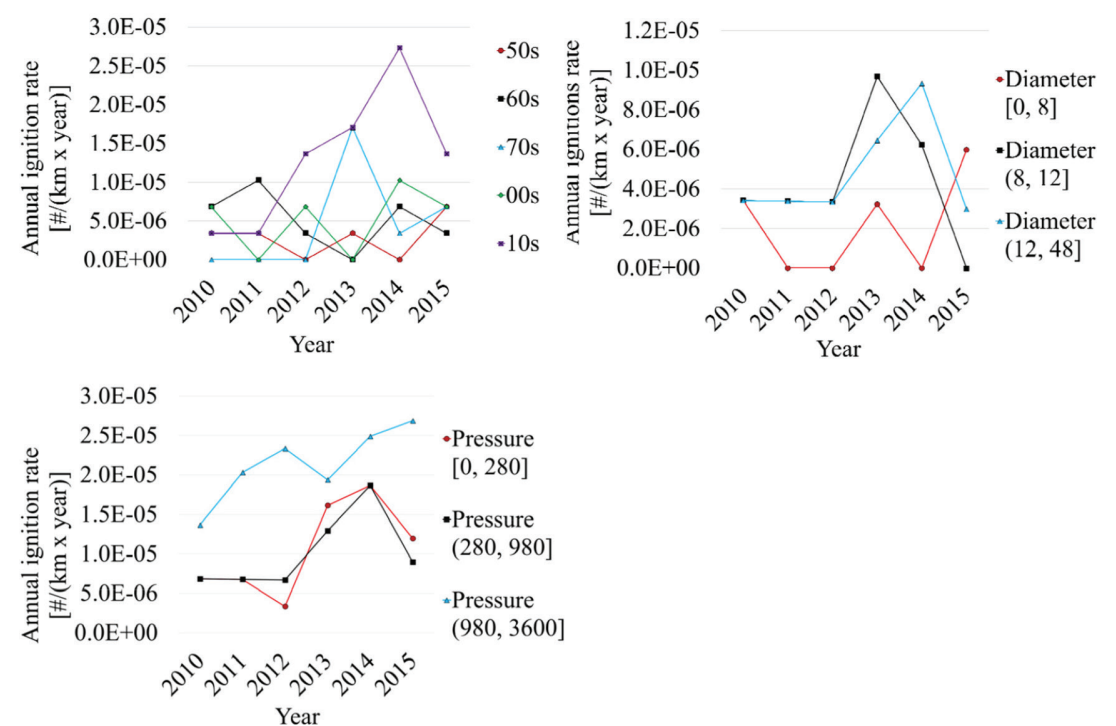

Figure 3: Annual number of ignitions for design variables per hazardous liquid pipelines.

reason, the analysis of relationships between pipeline design variables and ignition is focused on hazardous liquid pipelines in this section. Note that hazardous liquids pipelines are not divided into population classes. Figure 3 shows that larger diameters, higher MAOP, and recently installed pipelines have incresed ignition rates.

\subsection{Annual fatality and injury rate}

The major consequence of oil and gas pipeline failures are fatalities and injuries. Distribution pipelines have steady annual injury and fatality rates, as shown in Figure. 4. In fact, distribution lines are often located in areas with medium and high population densities, where the general public, such as residents, may be involved in accidents. Figure 5 shows the ratio of workers and general public involved in accidents. Similarly to Lam et al. [6], the general 


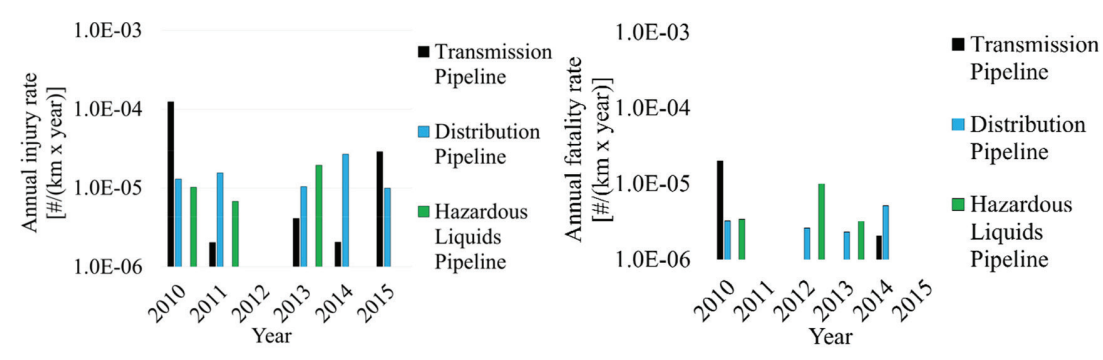

Figure 4: Annual injury and fatality rates per pipeline type.
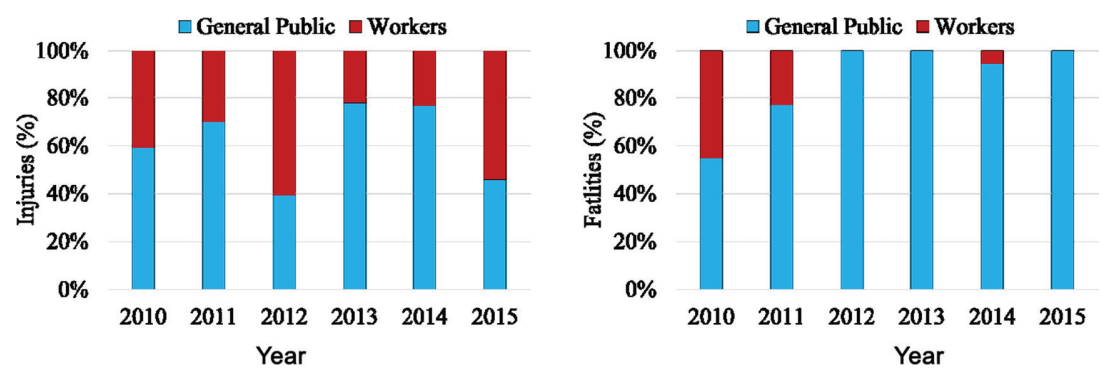

Figure 5: Annual percentage of workers and general public injured in distribution pipelines accidents.

public is larger affected than workers; only in 2012 one single event caused a higher number of injured workers.

Figure 6 focuses on the relationships between the pipe design variables and the injury rate. As a result, Classes 3 and 4, which are the most populated areas, have higher injury rates, as well as smaller diameter pipelines; all MAOP groups follow a similar trend over the time,
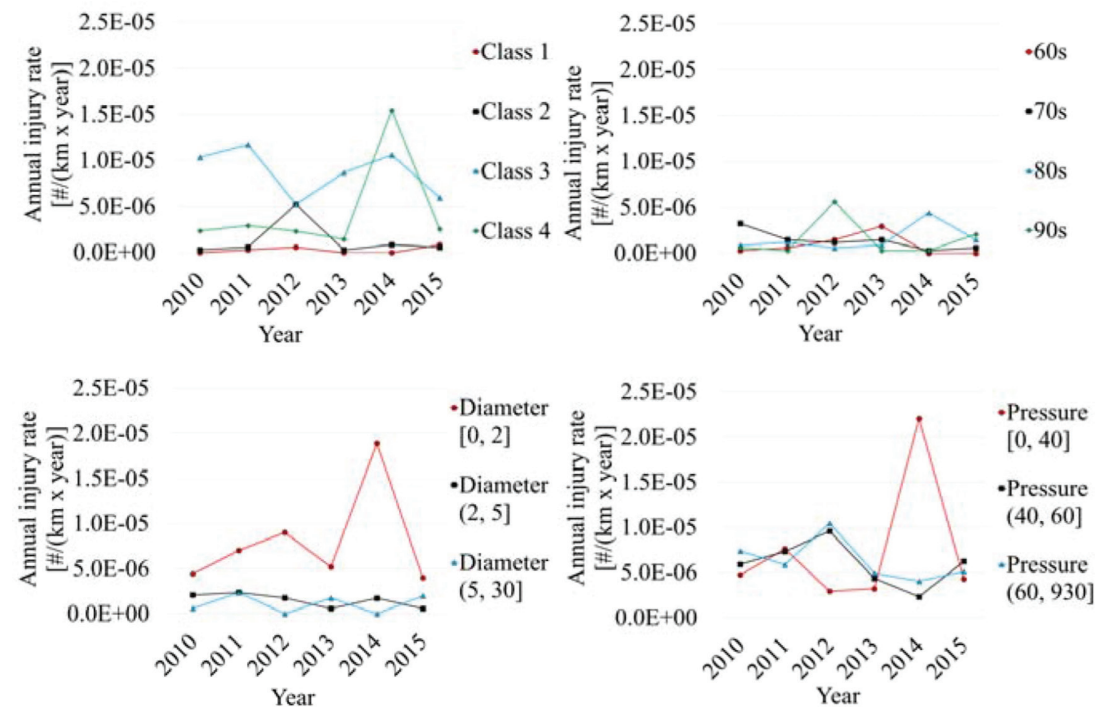

Figure 6: Annual number of injuries and fatalities for design variables for distribution pipelines. 
with the exception of low pressure pipelines in 2014. However, this peak seems consistent with the injury rate and the other design characteristics, since in 2014 the number of injuries is higher than other years.

\subsection{Property damage}

The total cost of gas pipelines does not consider the cost of gas lost while hazardous material pipelines include the cost of product lost, as reported in section 2.1. Figure 7 shows that gas transmission pipeline accidents generally resulted in the most expensive annual average property damages.

The total property damage includes estimated cost of public property damage, estimated cost of intentional and unintentional gas released, operators' damage and repairs, emergency response, and other costs. Figure 8 shows the trends resulting from the regression analyses. The regression line for the location class and installation years results quite steady, although lower classes, which represent less populated areas, and older installed pipelines generally lead to more expensive costs, with the exception of few isolated cases. Additionally, larger diameters cause more expensive property damage, and higher MAOPs result in higher costs in most cases.

\subsection{Spilled volume}

The volume of product released is measured in cubic feet for gas pipelines and in barrels for hazardous liquid pipelines. The distribution pipeline database does not provide this information and gathering lines does not contain a valuable number of releases to be considered as relevant in this section. From the environmental point of view, hazardous material releases are the most dangerous due to the toxic chemicals that they contain and they can lead to environmental impacts; for this reason, this section focuses on hazardous liquid pipelines.

The hazardous liquid pipeline incidents database provides information on unintentional and intentional release of product; this study only considers the unintentional quantity of material released.

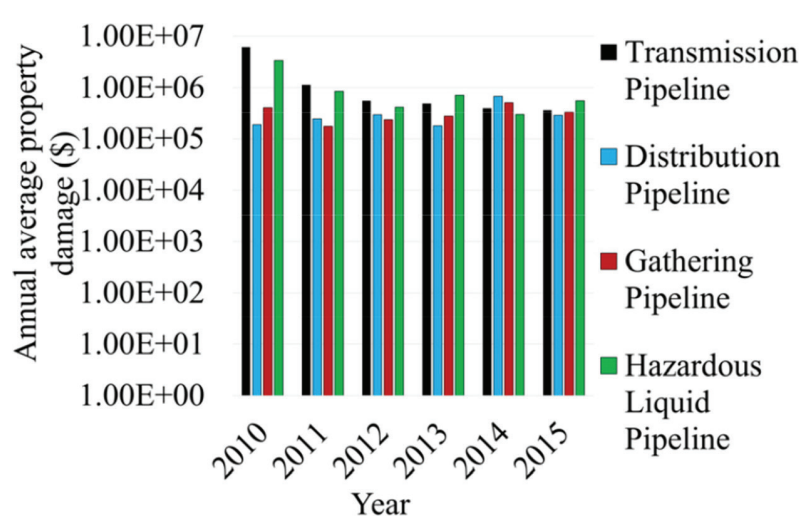

Figure 7: Annual average property damage per pipeline type. 

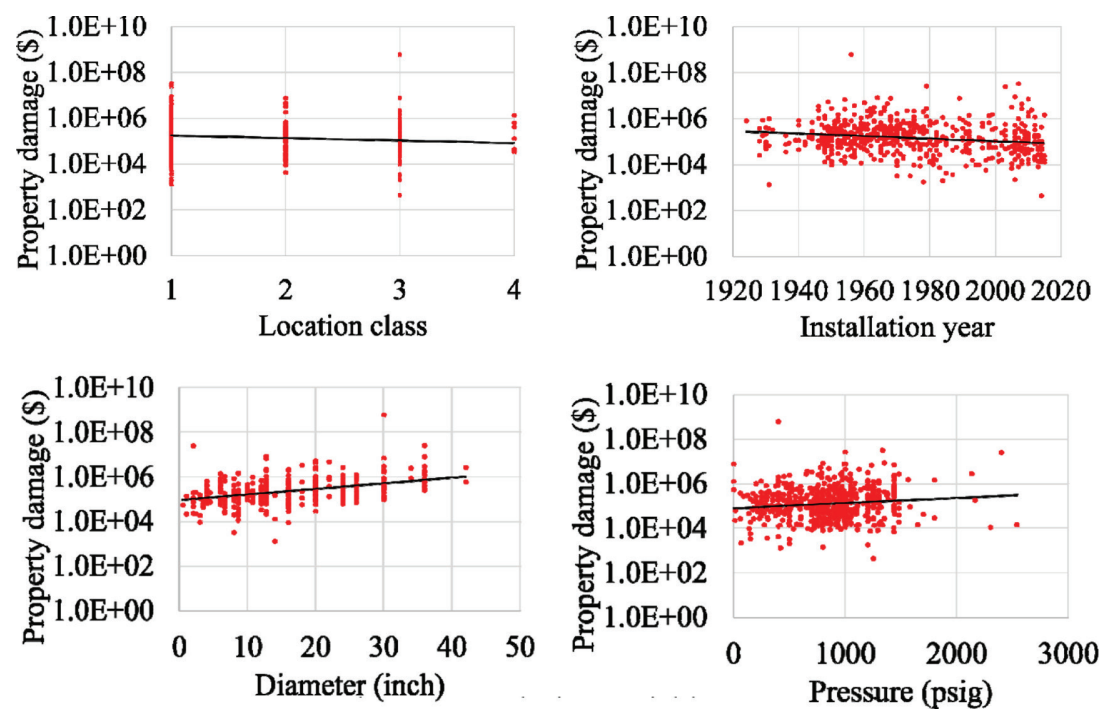

Figure 8: Property damage per design variables for transmission pipelines.
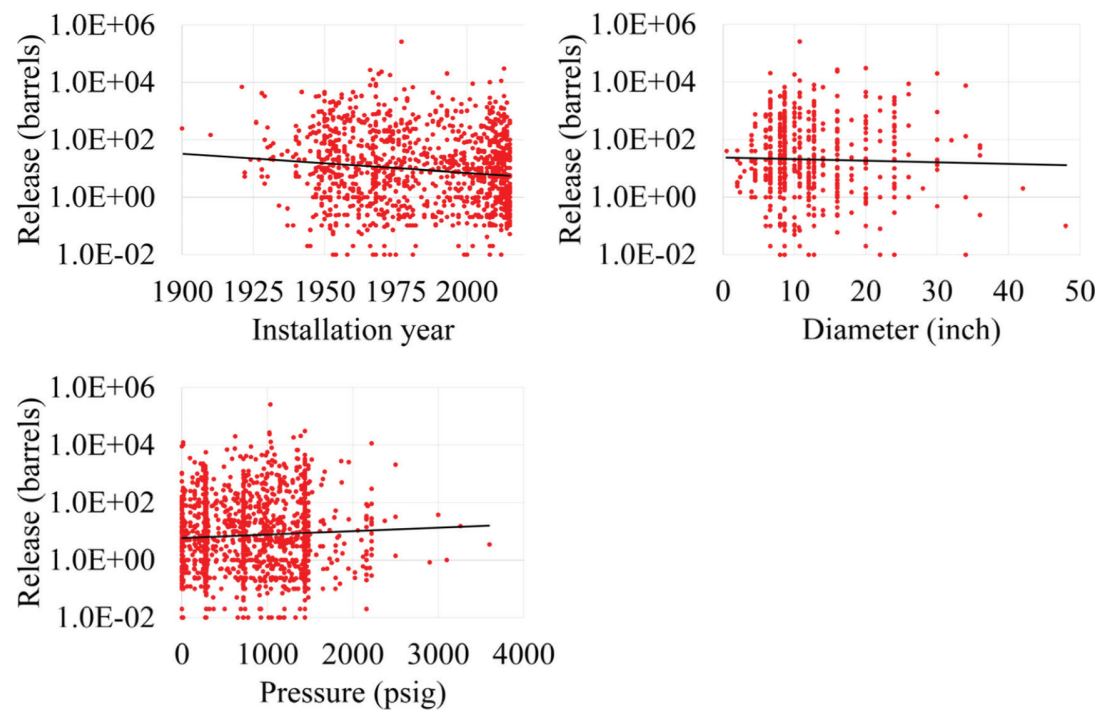

Figure 9: Unintentional released volume per design variables for hazardous liquid pipelines.

Figure 9 shows the scatter plot for the pipe design variables and the volumes of product released for hazardous liquid lines along with the regression line. Overall, product releases decrese with recent installed pipelines; smaller diameters and low and medium pressure pipelines result in most accidents, although the volume released increase with higher pressure pipelines.

\section{CONCLUSION}

This paper presents a statistical analysis of oil and gas pipeline failure event rates and consequences. Major pipeline incident events often result in ignitions, injuries, fatalities, 
property damage and release of hazardous materials. Pipeline design variables, such as class location, installation year, pipe diameter and maximum allowable operating pressure, were used as explanatory variables to estimate accident consequences. The results show that recently installed hazardous liquid pipelines of large diameters and high pressures have the largest ignition rates. Distribution pipelines of small diameters and located in high population density areas cause larger injury rates, especially affecting general public rather than workers. Furthermore, older installed transmission pipelines that fail in sparsely populated areas generally result in increased property damages. Finally, older installed hazardous liquid pipelines of smaller pipe diameters and higher maximum allowable operating pressures cause larger product releases in most of cases.

Based on this statistical analysis, probabilistic models may be developed in future works to calculate the probability of ignition, injury, property damage and spilled volume that may result in case of an accident. Moreover, future developments in this study will consider more pipeline design variables and will include other variables associated with pipeline failures, such as the type of release and the failure cause.

\section{ACKNOWLEDGEMENTS}

The authors gratefully acknowledge the financial support provided by NSERC.

\section{REFERENCES}

[1] Key world energy statistics; International Energy Agency, available at https://www.iea. org/publications/freepublications/publication/key-world-energy-statistics.html

[2] U.S. Department of Transportation (DOT), Pipeline and Hazardous Materials Safety Administration (PHMSA) Web Site, Washington DC.

[3] U.S. Department of Transportation (DOT), Pipeline and Hazardous Materials Safety Administration (PHMSA) Web Site, Washington DC.

[4] U.S. Government Publishing Office (GPO), Electronic Code of Federal Regulations (CFR), Title 49.

[5] Welded and seamless wrought steel pipe; The American Society of Mechanical Engineers (ASME), ASME B36.10M-2004.

[6] Lam, C. \& Zhou, W., Statistical analyses of incidents on onshore gas transmission pipelines based on PHMSA database. International Journal of Pressure Vessels and Piping, 145, pp. 29-40, 2016. https://doi.org/10.1016/j.ijpvp.2016.06.003 